\title{
A REVIEW ON THE BEGINNING, SPREADING AND TREATMENT OF CORONAVIRUS (COVID-19)
}

\author{
Sanjay Dohare \\ Faculty, Department of Biotechnology, Government Girls P. G. College of Excellence, \\ Sagar (M.P.), 470001, India \\ Rakesh Kumar Saket \\ Research scholar, Department of Biotechnology, Barkatullah University, \\ Bhopal (M.P.), India
}

\begin{abstract}
Wuhan, China was the first city of the glove where the coronavirus patients were found on 31 December in 2019. The SARS CoV-2 (n $\mathrm{CoV}$ ) is a $\beta$-coronavirus, the coronavirus disease 2019 (COVID-19) has spread throughout from China to other developed and developing continents. Sequencing results and evolutionary analysis, bat has been suspected as natural host of virus origin, and SARS CoV- 2 might be transmitted from bats. Human-to-human transmission of SARS-CoV-2 occurs. The size of SARS - CoV-2 is about $29.9 \mathrm{~Kb}$ lengths, SARS$\mathrm{CoV}$ is $27.9 \mathrm{~Kb}$ and MERS-CoV is $30.1 \mathrm{~kb}$, both have positive sense RNA genomes. Basic symptoms are seen in the patients like fever, malaise and dry cough and other respiratory failure, gastrointestinal symptoms, diarrhea, vomiting, fatigue. Diagnosis by RT- PCR (Reverse Transcriptase- Polymerase chain reaction) or Real time PCR. Remdesivir and Chloroquine drug with great potential to treat COVID-19. In Korea significantly decreased after lopinavir/ritonavir used. China including lopinavir/ritonavir, arbidol, used and gained significant improvement. The other antiviral drugs include nitazoxanide, favipiravir, nafamostat.
\end{abstract}

Keywords: COVID -19/ SARS CoV-2, Beginning, Spreading, Symptoms, Treatments, remdesivir, nitazoxanide, favipiravir, nafamostat.

\section{INTRODUCTION}

Wuhan, China was the first city of glove where a lots of pneumonia cases found. After examination, doctor's cleared that patients caused by a newly identified coronavirus on 31December 2019. This coronavirus, was initially named as the 2019-novel coronavirus (2019-nCoV) on 12 January 2020 by World Health Organization (WHO). WHO officially named the disease as coronavirus disease 2019 (COVID-19) and Coronavirus Study Group (CSG) of the International Committee recommended name the new Coronavirus as SARS-CoV-2. The scientists of China quickly isolated a SARS-CoV-2 from a patient within a short period of time on 7 January 2020 and done sequencing of the genome of SARS-CoV-2 [1]. At present, as of 7 April 2020, a total of 1214466, cases of COVID-19 have been confirmed in all over World including 67767cases of death, time 05;30 GMT $+5 ; 30$ [ 2]. In India a total confirmed cases is3981 and 114 death cases. (ministry of health India) at 7 April 2020 9;00GMT=5;30.It is estimated the basic reproduction number (R0) of SARS-CoV-2 to be around 2.2 [3], or even more (range from 1.4 to 6.5) [4].The epidemic COVID-19 steadily spreading by human-to-human transmission but it is zoonotic.

\section{Beginning and spreading of SARS-CoV-2}

The SARS-CoV-2 is a $\beta$-coronavirus, which is enveloped non-segmented positive-sense RNA virus (subgenus sarbecovirus, Orthocoronavirinae subfamily) [5]. Coronaviruses $(\mathrm{CoV})$ are classified into four categories, including $\alpha-/ \beta-/ \gamma-/ \delta-\mathrm{CoV}$, first two are able to infect mammals, while $\gamma-$ and $\delta-\mathrm{CoV}$ able to infect birds. The two known $\beta$-CoVs, SARS$\mathrm{CoV}$ and MERS-CoV lead to severe and potentially fatal respiratory tract infections [6]. The genomic sequence reveled that SARS-CoV-2 is $96.2 \%$ identical to a bat CoV RaTG13, shares $79.5 \%$ identity to SARS-CoV. On the basis of sequencing results and evolutionary analysis, bat has been suspected as natural host of virus origin, and SARS CoV- 2 might be transmitted from bats via unknown intermediate hosts to infect humans. It is clear now 
that SARS-CoV-2 could use angiotensin-converting enzyme 2 (ACE2), the same receptor as SARS-CoV
[7], to infect humans.

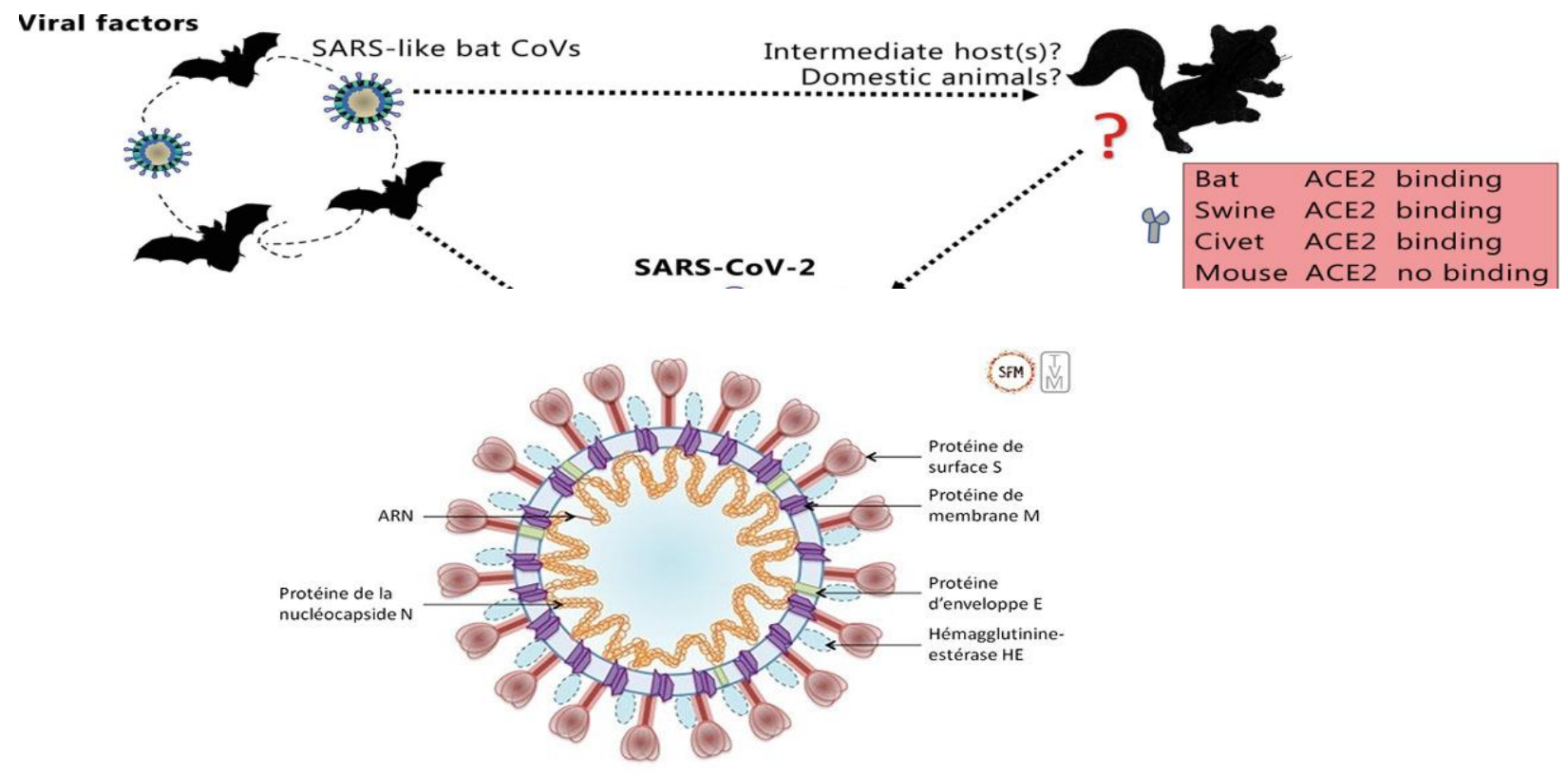

Figure: 1 Origin of SARS-CoV-2

\section{EPIDEMIOLOGY AND TRANSMISSION}

The epidemic of unknown acute respiratory tract infection broke out first in Wuhan, China, since 12 December 2019, related to a seafood market. Several studies suggested that bat may be the primary reservoir of SARS-CoV-2 [8, 9]. However, the origin of SARS-CoV-2 was from the seafood market has no evidence till now. Rather, bats are the primary or natural reservoir of a wide variety of CoVs, including SARS-CoV-like and MERS CoV- like viruses [10-12]. The viral genome sequencing of new coronavirus $(\mathrm{nCoV})$ was analyzed to Bat genome CoV RaTG13 and showed that $96.2 \%$ overall genome sequence is identical [7], suggesting that bat $\mathrm{CoV}$ and human SARS-CoV-2 might be same ancestor, although bats are not available for sale in this seafood market of China [13]. Besides, protein sequences alignment and phylogenetic analysis [14] showed that similar of receptors were observed in many species, which was of alternative intermediate hosts, such as pangolin, turtles and snacks.

Human-to-human transmission of SARS-CoV-2 occurs mainly between family members, including relatives and friends who contacted with patients or carriers peoples. It was found [15] that $31.3 \%$ of
Peoples recent travelled to Wuhan, China and $72.3 \%$ of peoples contacting with patients from Wuhan among the patients of nonresidents of Wuhan. Transmission between healthcare workers such as doctors, nurses occurred in 3.8\% of COVID-19 patients, issued by the National Health Commission of China on 14 February 2020. The transmission of SARS-CoV and MERS-CoV is reported to occur mainly through nosocomial transmission. Infections of healthcare workers in 33-42\% of SARS cases and transmission between patients $(62-79 \%)$ were the most common route of infection in MERS-CoV cases $[16,17]$. Intermediate host animals or consumption of wild animals was suspected to be the main route of SARS-CoV-2 transmission. However, the sources, transmission routine(s) of SARS-CoV-2 remain unclear.

\section{GENOMIC STRUCTURE OF nCoV}

The size of SARS $-\mathrm{CoV}-2$ is about $29.9 \mathrm{~Kb}$ lengths, SARS- $\mathrm{CoV}$ is $27.9 \mathrm{~Kb}$ and MERS- $\mathrm{CoV}$ is $30.1 \mathrm{~kb}$, both have positive sense RNA genomes [18]. Mutation done on non structural protein, NSP2 and SARS CoV-2 had been mutated in different patients in China and it is smaller than H7N9 avian influenza. Basically Corona or COVID-19 is two type, L type (70\%) and $\mathrm{S}$ type (30\%).L type strain are derived 
from $S$ type which is more aggressive and contagious. [19, 20]

\section{CLINICAL CHARACTERISTICS}

Sars CoV -2 was isolated from fecal swabs of a severe pneumonia patients on 10 February 2020 from china [21]. The incubation period is 1-14 days (3-7 day). COVID -19 is highly transmitted to elderly with underlying disease (old man with suffer from any disease). The median age of patients is $47.9-45.7 \%$ patients with female so the suffering from COVID 19 , both gender are equally target. [22, 23]

\section{SYMPTOMS}

There are three basic symptoms are seen in the patients, fever, malaise and dry cough. Other Symptoms like respiratory failure, gastrointestinal symptoms, diarrhea, vomiting, fatigue, and sputum production, shortness of breath, sore throat and headache are also reported. Out of all these symptoms patient suffering from fever is about $88.7 \%$, cough $67.8 \%$ and fatigue $38.1 \%$. Fisrt two symptoms are dominated. [15]

\section{DIAGNOSIS OF SARS COV-2}

The primarily identification of SARS- CoV-2 through classical Koch's postulates by observing its morphology through electron microscope [24]and most advance common diagnosis methods are molecular methods as RT- PCR (Reverse Transcriptase-Polymerase chain reaction) or Real time PCR, which are made using RNA from respiratory surface samples such as oropharyngeal swabs, or bronchoalveolar lavage and sputum.

Novel Coronavirus (nCoV) like SARS $\mathrm{CoV}$ and MERS CoV so the diagnosis procedure follows same SARS CoV and MERS CoV. Virology and genetic analysis studies have shown that bats are reservoir hosts of both SARS CoV and MERS CoV. Bat gene source of alpha $\mathrm{CoV}$ and beta $\mathrm{CoV}$.

\section{TREATMENT AND PROTECTION}

Given the lack of effective antiviral therapy against COVID-19, current treatments mainly focused on symptomatic and respiratory support according to the Diagnosis and Treatment of Pneumonia Caused by COVID-19 (updated to version 6) issued by National Health Commission of the People's Republic of China [25]. Nearly all patients accepted oxygen therapy, and WHO recommended extracorporeal membrane oxygenation (ECMO) to patients with refractory hypoxemia [26]. Rescue treatment with convalescent plasma and immunoglobulin G [27] are delivered to some critical cases according to their conditions.

\section{ANTIVIRAL TREATMENTS}

Based on the experience of fighting the epidemic SARSCoV and MERS-CoV previously, we may learn some lessons for some treatment strategies against coronavirus [28]. Antiviral drugs and systemic corticosteroid treatment commonly used in clinical practice previously, including neuraminidase inhibitors (oseltamivir, peramivir, zanamivir, etc), ganciclovir, acyclovir, and ribavirin, as well as methylprednisolone [29] for influenza virus, are invalid for COVID-19 and not recommended. Remdesivir is a 1'-cyano-substituted adenosine nucleotide analog prodrug and shows broad-spectrum antiviral activity against several RNA viruses. Based on the data collected from in vitro cell line and mouse model, remdesivir could interfere with the NSP12 polymerase even in the setting of intact ExoN proofreading activity [30]. Remdesivir has been reported to treat the first US case of COVID-19 successfully [31]. Chloroquine is a repurposed drug with great potential to treat COVID-19. Chloroquine has been used to treat malaria for many years [32], with a mechanism that is not well understood against some viral infections. Several possible mechanisms are investigated: Chloroquine can inhibit $\mathrm{pH}-$ dependent steps of the replication of several viruses [33], with a potent effect on SARS-CoV infection and spread [34]. Moreover, chloroquine has immunomodulatory effects, suppressing the production/release of TNF- $\alpha$ and IL-6. It also works as a novel class of autophagy inhibitor [35], which may interfere with viral infection and replication. Several studies have found that chloroquine interfered with the glycosylation of cellular receptors of SARS-CoV [34] and functioned at both entry and at post-entry stages of the COVID-19 infection in Vero E6 cells [36]. A combination of remdesivir and chloroquine was proven to effectively inhibit the recently emerged SARS-CoV-2 in vitro.

Scientists previously confirmed that the protease inhibitors lopinavir and ritonavir, used to treat infection with human immunodeficiency virus (HIV) [37], could improve the outcome of MERS-CoV [38] and SARSCoV [39] patients. It has reported that $\beta$ coronavirus viral loads of a COVID-19 patient in Korea significantly decreased after lopinavir/ritonavir (Kaletra®, AbbVie, North Chicago, IL, USA) 
treatment [40]. Additionally, clinicians combined Chinese and Western medicine treatment including lopinavir/ritonavir (Kaletra®), arbidol, and Shufeng Jiedu Capsule (SFJDC, a traditional Chinese medicine) and gained significant improvement in pneumonia associated symptoms in Shanghai Public Health Clinical Center, China [41].The other antiviral drugs include nitazoxanide, favipiravir, nafamostat.

Many measures should be taken, such as timely publication of epidemic information for elimination of the source of infection, early diagnosis, reporting, isolation, supportive treatments and for avoiding unnecessary panic. CDC reminds basic measures such as hand washing, using disinfectant solutions, avoiding contact with patients in order to prevent the spread of viruses by droplets. Precautionary actions including the provision of medicines supply chains, personal protective equipment, and hospital supplies should be made in a short time for the protection of the Chinese people and global health, especially in the places with close travel ports to major Chinese ports.

Based on the 2003 SARS-CoV epidemic experience, the government takes many effective measures including closing public transport, reducing migration and promoting personal protection with masks in Wuhan and other provinces. Hence, there are reported cases of infected hospital personnel, healthcare staff should be informed about taking personal protective measures such as the use of gloves, eye masks and N95 masks during the examination of patients with a suspected history of COVID-19 contact or travel to China.

\section{ACKNOWLEDGEMENT}

The authors thank principal, Dr. B. D. Ahirwar and Dr. Sunita Singh, Head of the Zoology and Biotechnology, Government Girls Post Graduate College of Excellence, Sagar, (MP) India, for giving us encouragement and guidance in preparing the manuscript.

\section{REFERENCES}

1. Lu R, Zhao X, Li J, Niu P, Yang B, Wu H, et al. (2020). Genomic characterization and epidemiology of 2019 novel coronavirus: implications for virus origins and receptor binding. Lancet, 395(10224), (pp.565-74).

2. World Health Organization (2020). Coronavirus disease (COVID-2019) situation reports 2020. https://who.int/emergencies/diseases/novelcoronavirus-2019/situationreports.

3. Riou J., Althaus CL.(2020). Pattern of early human-to-human transmission of Wuhan 2019 novel coronavirus (2019-nCoV), December 2019 to January 2020, Euro Surveill. 25(4), 2000058.

4. Liu Y, Gayle AA, Wilder-Smith A, Rocklov J. (2020). The reproductive number of COVID-19 is higher compared to SARS coronavirus. J Travel Med, https://doi.org/10.1093/jtm/taaa021.

5. Zhu N, Zhang D, Wang W, Li X, Yang B, Song J, et al.(2020). A novel coronavirus from patients with pneumonia in China, 2019, N Engl J Med, 382(8), (pp. 727-33).

6. Yin Y, Wunderink RG. (2018). MERS, SARS and other coronaviruses as causes of pneumonia. Respirology. 23(2), (pp. 130-137).

7. Zhou P, Yang XL, Wang XG, Hu B, Zhang L, Zhang W, et al.(2020). A pneumonia outbreak associated with a new coronavirus of probable bat origin, Nature, https://doi.org/10.1038/s41586020-2012-7.

8. Giovanetti M, Benvenuto D, Angeletti S, Ciccozzi M. (2020).The first two cases of 2019-nCoV in Italy: where they come from?, J Med Virol, (pp.17).

9. Paraskevis D, Kostaki EG, Magiorkinis G, Panayiotakopoulos G, Sourvinos G, Tsiodras S.,(2020). Full-genome evolutionary analysis of the novel corona virus (2019-nCoV) rejects the hypothesis of emergence as a result of a recent recombination event, Infect Genet Evol. 79,104212 .

10. Hampton T. (2005). Bats may be SARS reservoir, JAMA, 294(18), 2291.

11. Banerjee A, Kulcsar K, Misra V, Frieman M, Mossman K. (2019).Bats and coronaviruses. Viruses, 11(1), E41, https://doi.org/10.3390/v11010041.

12. Li W, Shi Z, Yu M, Ren W, Smith C, Epstein JH, et al.(2005). Bats are natural reservoirs of SARSlike coronaviruses. Science, 310(5748), (pp.676679).

13.Wu F, Zhao S, Yu B, Chen YM, Wang W, Song $\mathrm{ZG}$, et al.(2020). A new coronavirus associated with human respiratory disease in China. Nature,https://doi.org/10.1038/s41586-0202008-3.

14.Liu Z, Xiao X, Wei X, Li J, Yang J, Tan H, et al. (2020). Composition and divergence of coronavirus spike proteins and host ACE2 receptors predict potential intermediate hosts of SARS-CoV-2. J Med Virol, https://doi.org/10.1002/jmv.25726. 
15.Guan WJ, Ni ZY, Hu Y, Liang WH, Ou CQ, He JX, et al. (2020).Clinical characteristics of coronavirus disease 2019 in China. N Engl J Med, https://doi.org/10.1056/NEJMoa2002032.

16. Chowell G, Abdirizak F, Lee S, Lee J, Jung E, Nishiura H, et al. (2015). Transmission characteristics of MERS and SARS in the healthcare setting: a comparative study. BMC Med. 13, 210.

17. Kang CK, Song KH, Choe PG, Park WB, Bang JH, Kim ES, et al.(2017).Clinical and epidemiologic characteristics of spreaders of middle east respiratory syndrome coronavirus during the 2015 outbreak in Korea. J Korean Med Sci., 32(5), (pp. 744-749).

18. de Wit E, van Doremalen N, Falzarano D, Munster VJ. (2016). SARS and MERS: recent insights into emerging coronaviruses. Nat Rev Microbiol. 14(8), (pp.523-534).

19. Wu D, Zou S, Bai T, Li J, Zhao X, Yang L, et al. (2015). Poultry farms as a source of avian influenza a (H7N9) virus reassortment and human infection. Sci Rep., 5, 7630.

20. Tang X, Wu C, Li X, Song Y, Yao X, Wu X, et al. (2020).On the origin and continuing evolution of SARS-CoV-2. Natl Sci Rev., https://doi.org/10.1093/nsr/nwaa036.

21. Zhang W, Du RH, Li B, Zheng XS, Yang XL, $\mathrm{Hu}$ B, et al. (2020). Molecular and serological investigation of $2019-\mathrm{nCoV}$ infected patients: implication of multiple shedding routes. Emerg Microbes Infect. 9(1), (pp.386-689).

22. Li Q, Guan X, Wu P, Wang X, Zhou L, Tong Y, et al. (2020). Early transmission dynamics in Wuhan, China, of novel coronavirus-infected pneumonia, $\mathrm{N}$ Engl J Med, https://doi.org/10.1056/NEJMoa2001316.

23. Wang D, Hu B, Hu C, Zhu F, Liu X, Zhang J, et al.(2020). Clinical characteristics of 138 hospitalized patients with 2019 novel coronavirus-infected pneumonia in Wuhan, China, JAMA, https://doi.org/10.1001/jama.2020.1585.

24. Lu H, Stratton CW, Tang YW.(2020). Outbreak of pneumonia of unknown etiology in Wuhan, China: the mystery and the miracle. J Med Virol, 92(4), (pp. 401-402).

25. National Health Commission of the People's Republic of China. (2020). Diagnosis and Treatment of Pneumonia Caused by 2019$\mathrm{nCoV}$ (version 6).[ONLINE]

26. WHO. (2020). Clinical management of severe acute respiratory infection when novel coronavirus (nCoV) infection is suspected. [ONLINE].
27. Chen L, Xiong J, Bao L, Shi Y. (2020). Convalescent plasma as a potential therapy for COVID-19, Lancet Infect Dis., https://doi.org/10.1016/s1473-3099(20)301419.

28. Zumla A, Chan JF, Azhar EI, Hui DS, Yuen KY. (2016). Coronaviruses - drug discovery and therapeutic options. Nat Rev Drug Discov, 15(5), (pp.327-347.)

29. Li H, Wang YM, Xu JY, Cao B.(2020). Potential antiviral therapeutics for 2019 Novel Coronavirus. Chin J Tuberc Respir Dis, 43(0), E002.

30. Agostini ML, Andres EL, Sims AC, Graham RL, Sheahan TP, Lu X, et al.(2018). Coronavirus susceptibility to the antiviral remdesivir (gs5734) is mediated by the viral polymerase and the proofreading exoribonuclease, mBio, 9(2), e00221-18, https://doi.org/10.1128/mBio.00221-18.

31. Holshue ML, DeBolt C, Lindquist S, Lofy KH, Wiesman J, Bruce H, et al. (2020). First case of 2019 novel coronavirus in the United States, N Engl J Med, https://doi.org/10.1056/NEJMoa2001191.

32. Aguiar ACC, Murce E, Cortopassi WA, Pimentel AS, Almeida M, Barros DCS, et al.(2018). Chloroquine analogs as antimalarial candidates with potent in vitro and in vivo activity, Int $\mathbf{J}$ Parasitol Drugs Drug Resist. 8(3), (pp.459464).

33. Savarino A, Boelaert JR, Cassone A, Majori G, Cauda R.(2003). Effects of chloroquine on viral infections: an old drug against today's diseases?, Lancet Infect Dis. 3(11), (pp.722727).

34. Vincent MJ, Bergeron E, Benjannet S, Erickson BR, Rollin PE, Ksiazek TG, et al.(2005).

Chloroquine is a potent inhibitor of SARS coronavirus infection and spread, Virol J, 2, 69.

35. Golden EB, Cho HY, Hofman FM, Louie SG, Schonthal AH, Chen TC. (2015). Quinolinebased antimalarial drugs: a novel class of autophagy inhibitors, Neurosurg Focus, 38(3), E12.

36. Wang M, Cao R, Zhang L, Yang X, Liu J, Xu M, et al. (2020). Remdesivir and chloroquine effectively inhibit the recently emerged novel coronavirus (2019-nCoV) in vitro, Cell Res., https://doi.org/10.1038/s41422-020-0282-0.

37. Cvetkovic RS, Goa KL.,(2003). Lopinavir/ritonavir: a review of its use in the management of HIV infection. Drugs, 63(8), (pp.769-802). 
38. Arabi YM, Asiri AY, Assiri AM, Aziz Jokhdar HA, Alothman A, Balkhy HH, et al. (2020). Treatment of Middle East respiratory syndrome with a combination of lopinavir/ritonavir and interferon- $\beta 1 b$ (MIRACLE trial): statistical analysis plan for a recursive two-stage group sequential randomized controlled trial, Trials, 21(1), 8.

39. Chu CM, Cheng VC, Hung IF, Wong MM, Chan KH, Chan KS, et al. (2004). Role of lopinavir/ritonavir in the treatment of SARS: initial virological and clinical findings, Thorax, 59(3), (pp.252-526).

40. Lim J, Jeon S, Shin HY, Kim MJ, Seong YM, Lee WJ, et al.(2020). Case of the index patient who caused tertiary transmission of COVID-19 infection in Korea: the application of lopinavir/ritonavir for the treatment of COVID19 infected pneumonia monitored by quantitative RT-PCR, J Korean Med Sci., 35(6), e79.

41. Wang Z, Chen X, Lu Y, Chen F, Zhang W. (2020). Clinical characteristics and therapeutic procedure for four cases with 2019 novel coronavirus pneumonia receiving combined Chinese and Western medicine treatment, Biosci

Trends,https://doi.org/10.5582/bst.2020.01030. 